\title{
TOWARDS A TAXONOMY OF LEGAL EDUCATION RESEARCH
}

\author{
Kate Galloway, ${ }^{*}$ Melissa Castan, ${ }^{* *}$ Alex Steel $^{* * *}$
}

The purpose, content, and approach of legal education together create the lawyer many of our students will become. Beyond discipline knowledge, the skills and attitudes the law graduate brings to the profession find their foundation in the experiences of the student in law school. In turn, through their actions in legal practice, the law graduate-cum-lawyer turns dry words into real social structures and powers and so performs, and arguably, creates the law. From a different perspective, theories of education that are applied in law school - consciously or unconsciouslyinculcate in students particular ways of engaging with the law. Such training inevitably informs approaches to legal scholarship, itself a recognised component of a functioning legal system. ${ }^{1}$ Legal education is thus not only integral to law but might validly be seen as a constitutive part of law itself.

Legal education has long been fundamental to the development of the law and its understanding of itself. Blackstone's Commentaries began as university lectures, as did many of the leading treatises and textbooks. It was the process of teaching law students that sparked the impetus to catalogue and systematize the law, and then influenced practitioners and courts. ${ }^{2}$ Legal change and development have also long been associated with law schools. ${ }^{3}$ Much legal scholarship remains research influenced and developed within teaching environments. Community legal centres in Australia are strongly supported and developed by legal education - whether through management by law schools or through student volunteers. ${ }^{4}$

Similarly, when practitioners see failings in the profession, they often turn to law schools to introduce innovations to deal with the issues: three examples are increasing statutory interpretation skills, ${ }^{5}$ developing writing programs, and addressing issues of wellbeing. ${ }^{6}$

Areas of law not taught in core law school subjects are seen as academic specialties (and those taught in the core subjects are seen as the expected knowledge of all

\footnotetext{
* Associate Professor, Co-Director Centre of Professional Legal Education, Faculty of Law, Bond University.

** Associate Professor, Faculty of Law, Monash University.

${ }^{* * *}$ Professor, Faculty of Law, University of New South Wales.

${ }^{1}$ See eg Michael Kirby, 'Welcome to Law Reviews' (2002) 26(1) Melbourne University Law Review 1.

${ }^{2}$ See the review in David Sugarman, 'A Special Relationship? American Influences on English Legal Education, c. 1870-1965’ (2011) 18(1-2) International Journal of the Legal Profession 7.

${ }^{3}$ See, eg, David Barker, A History of Australian Legal Education (Federation Press, 2017).

${ }^{4}$ See, eg, Community Legal Centre Guide 2016-2017, Kingsford Legal Centre, UNSW Sydney 2016

$<$ http://www.klc.unsw.edu.au/sites/klc.unsw.edu.au/files/2676\%20CLE\%20guide_WEB.pdf $>$.

${ }^{5}$ Law Admissions Consultation Committee, 'Statement on Statutory Interpretation' (2010)

$<$ https://www.lawcouncil.asn.au/files/webpdf/LACC\%20docs/StatementonStatutoryInterpretation.pdf $>$.

${ }^{6}$ See, eg, the collaboration between major law firms and the College of Law in the Resilience @ Law program $<$ https://www.collaw.edu.au/learn-with-us/our-programs/practical-legal-trainingprograms/coursework/resilience>; Laura Helm, Mental Health and the Legal Profession: A Preventative Strategy (Law Institute of Victoria, 2014), 16.
} 
lawyers), approaches to legal reasoning and research are heavily influenced by teaching methods, and the types of academics employed by law schools have a direct impact on the nature and scope of legal scholarship available to the profession. Consequently, legal education has direct impacts on how law is understood, and how the legal profession sees itself.

Because legal education is so central to the idea of law and itself a constituent part of law, the debates within law including about its purpose - positivist, doctrinal, critical, normative, etc - are reflected within legal education. By extension, these positions are reflected within the scholarship of legal education ('SoLE') whether explicitly or implicitly: where the educational standpoint of a legal education scholar reflects their own discipline identity and commitment to the law. The positions adopted by a writer will also reflect the academic's idea of how knowledge is formed and the role of authority in society, positions that engage with broader understanding of law in society. Just as legal scholarship reflects diverse forms and perspectives, so too will SoLE. These standpoints all form part of the 'performance' of law.

This chapter first provides an overview of our project to develop a taxonomy of SoLE. The second part then articulates what is meant by legal research-itself a contested domain. We make the claim in the third part that (legal) educational research is a potentially interdisciplinary contribution to legal research. Importantly, this part spells out not only the disciplinary features of educational research, but also key education research methods. In the fourth part we extrapolate from the previous two parts to chart the likely territory of legal education research, identifying the key components of the field. We next focus on one aspect of the overarching taxonomy, exploring the dimensions of legal education themes. Finally, we draw together these frameworks to offer a means of comprehending SoLE as legal research.

\section{THE PROJECT}

The aim of the SoLE project is to recognise and chart the diversity of SoLE. In doing so, the resulting taxonomy is designed to make explicit the methods, approaches, purposes and subjects of SoLE as a reflection of the intersection of scholars' discipline practices in both law and education, as both teachers and as researchers, as both lawyers and academics. Through description and theorization of legal education research, it substantiates the contribution of SoLE to the legal academy, and to law and legal practice, within an explicit research framework. Ultimately it aims to establish SoLE as a domain of legal research.

This chapter reports on the first stage of the SoLE taxonomy project. We take taxonomy to mean the systematic classification of areas of knowledge. Taxonomies, otherwise known as classifications, differ from inventories in that they are linked via a logical structure. ${ }^{7}$ Library $^{8}$ and scientific ${ }^{9}$ classification, as well as Bloom's wellknown educational taxonomy, require distinct classes that are mutually exclusive, arranged in a hierarchical or other logical order and be arranged by level of

\footnotetext{
${ }^{7}$ Robert MW Travers, ‘Taxonomies of Educational Objectives and Theories of Classification' (1980) 2(2) Educational Evaluation and Policy Analysis 5.

${ }^{8}$ See, eg, J Mills, A Modern Outline of Library Classification (Asia Publishing House, 1960),

${ }^{9}$ See, eg, Ludo Waltman and Nees Jan van Eck, 'A New Methodology for Constructing a Publicationlevel Classification System of Science’ (2012) arXiv:1203.0532 [cs.DL].
} 
complexity or detail. ${ }^{10}$ Further, taxonomies should not merely attempt to reflect current understanding, but should draw on theoretical perspectives to provide suggestions for further research. ${ }^{11}$ Certainly, classifications will reflect the times in which they are developed. As Mills points out, 'a modern classification of chemistry will lack a heading for alchemy'. ${ }^{12}$ Similarly, Bloom's taxonomy has undergone further iterations in terms of the digital learning environment. ${ }^{13}$ While representing a point in time, they should have the capacity to grow with the discipline.

This pilot phase of the project - and the subject matter of this chapter-involves the first step of labelling. In subsequent iterations of the process, we will test the relatedness of publications ${ }^{14}$ and finally we envisage the capacity of the taxonomy to cluster publications within the layered themes, methods, and perspectives of the larger taxonomy.

Largely, and notably at this initial stage of the project, our method involves drawing on our experience as scholars in legal education to chart a prototype taxonomy. We acknowledge however, that the role of subject-matter expertise is contested as a means of developing a classification. Mills, for example, argues that classification of specialist fields requires an expert classificationist. ${ }^{15}$ Waltman and van Eck on the other hand, acknowledge the role of subject-matter experts in refining subject-matter labels. ${ }^{16}$ In light in particular of the omission of SoLE from contemporary research taxonomies such as the Australia and New Zealand Standard Research

Classification, ${ }^{17}$ and the preference for substantive legal research within the academy, we maintain that subject-matter expertise is a valid starting point for a new taxonomy.

Our first step has therefore been to anticipate what we describe as the domains of SoLE. We recognized early the combination of educational research methods, what we describe as 'perspectives' of the work, and the legal education themes per se. In other words, our hypothesised taxonomy comprises three distinct components, each of which bears its own internal structure and likely connections.

We have so far developed a prototype taxonomy by drawing on existing models of legal education, ${ }^{18}$ and from the broader scholarship of education; ${ }^{19}$ identifying divisions and connections between existing research and possible research suggested

\footnotetext{
${ }^{10}$ See eg Peter W Hill, 'Testing Hierarchy in Educational Taxonomies: A Theoretical and Empirical Investigation' (1984) 8(3) Evaluation in Education 179.

${ }^{11}$ Travers, above $\mathrm{n} 7$.

${ }^{12}$ Mills, above n Error! Bookmark not defined., 9.

${ }^{13}$ See, eg, Andrew Churches, 'Bloom's Taxonomy Blooms Digitally' (2008) 1 Tech \& Learning 1.

${ }^{14}$ A classification does not 'merely locate specific items but also relate[s] them helpfully': Mills, above n Error! Bookmark not defined., 6.

${ }^{15}$ Mills, above n Error! Bookmark not defined., 267.

${ }^{16}$ Waltman and van Eck, above n Error! Bookmark not defined.

${ }^{17}$ Australian Bureau of Statistics, 1297.0 - Australian and New Zealand Standard Research Classification (ANZSRC) (2008).

${ }^{18}$ For example, Nickolas James, Power-Knowledge and Critique in Australian Legal Education: 19872003 (Queensland University of Technology, 2004)

$<$ https://eprints.qut.edu.au/15910/1/Nickolas_James_Thesis.pdf $>$; Sally Kift, Mark Israel and Rachael Field, 'Bachelor of Laws Learning and Teaching Academic Standards Statement' (Australian Learning and Teaching Council, 2010).

${ }^{19}$ See, eg, Malcolm Tight, Researching Higher Education (SRHE \&Open University Press, 2003) who presents a taxonomy of higher education more broadly.
} 
by the theoretical models; and arranging those divisions in ways that highlight connections and arrange the divisions from broadest to narrowest. ${ }^{20}$

We started with an anticipated list of perspectives and themes, drawing on our expectation of what we would find in the literature and we tested this list against a small sample of legal education literature. While our original pilot project design anticipated classification of works in the Legal Education Review over a decade, we have instead relied on a smaller and manageable sample of works over the two most recent editions (2016-2017). We worked individually and then together, developing a shared understanding of the likely categories and testing these against the contents of these two editions.

This exercise has resulted in a hypothesized taxonomy: a starting point for engaging in a broader and deeper examination of the literature to test the replicability of the classifications, to test and reinforce connections and divisions, and ultimately for us, to establish a connection between SoLE and legal research itself.

\section{LEGAL RESEARCH}

Underpinning this investigation is a fairly persistent question concerning the nature of legal research. The Council of Australian Law Deans ('CALD'), for example, says that, 'It is not at all obvious what "legal research" comprehends' ${ }^{21}$ Further, CALD acknowledges the ongoing evolution of legal research notably as it straddles humanities and social sciences, increasingly comprises inter-disciplinary inquiries, and involves both academic and professional contexts. Siems and Mac Sithigh have thus suggested a tripartite division of legal education between "law as a practical discipline", "law as humanities" and "law as social sciences." 22

The Pearce Report identified that legal research in Australian universities was originally driven by practitioner models of research: it was largely doctrinal, namely:

Research which provides a systematic exposition of the rules governing a particular legal category, analyses the relationship between rules, explains areas of difficulty and, perhaps, predicts future developments. ${ }^{23}$

Pearce itself had drawn on an earlier and widely-adopted account of legal method, in the Canadian Arthurs Report. ${ }^{24}$ Of relevance, Arthurs proposed a taxonomy of legal research (Figure 1). ${ }^{25}$

\footnotetext{
${ }^{20}$ This draws on the approach in William R Veal and James G MaKinster, 'Pedagogical Content Knowledge Taxonomies' (1999) 3(4) Electronic Journal of Science Education

$<$ http://ejse.southwestern.edu/article/view/7615 $>$ which in turn is based on the approach taken by Bloom et al; Benjamin Samuel Bloom, Committee of College and University Examiners, Taxonomy of Educational Objectives (Longmans, Green New York, 1964) vol 2.

${ }^{21}$ Council of Australian Law Deans, 'Statement on the Nature of Legal Research' (October 2005).

${ }^{22}$ Mathias M Siems and Daithí Mac Síthigh, 'Mapping Legal Research' (2012) 71(3) The Cambridge Law Journal 651.

${ }^{23}$ Dennis Pearce, Enid Campbell and Don Harding ('Pearce Committee'), Australian Law Schools: A Discipline Assessment for the Commonwealth Tertiary Education Commission (1987), 6.

${ }^{24}$ H W Arthurs, Law and Learning: Report to the Social Sciences and Humanities Research Council of Canada by the Consultative Group on Research and Education in Law (Information Division, Social Sciences and Humanities Research Council of Canada, 1983).

25 Ibid 63-71.
} 


\section{Figure 1}

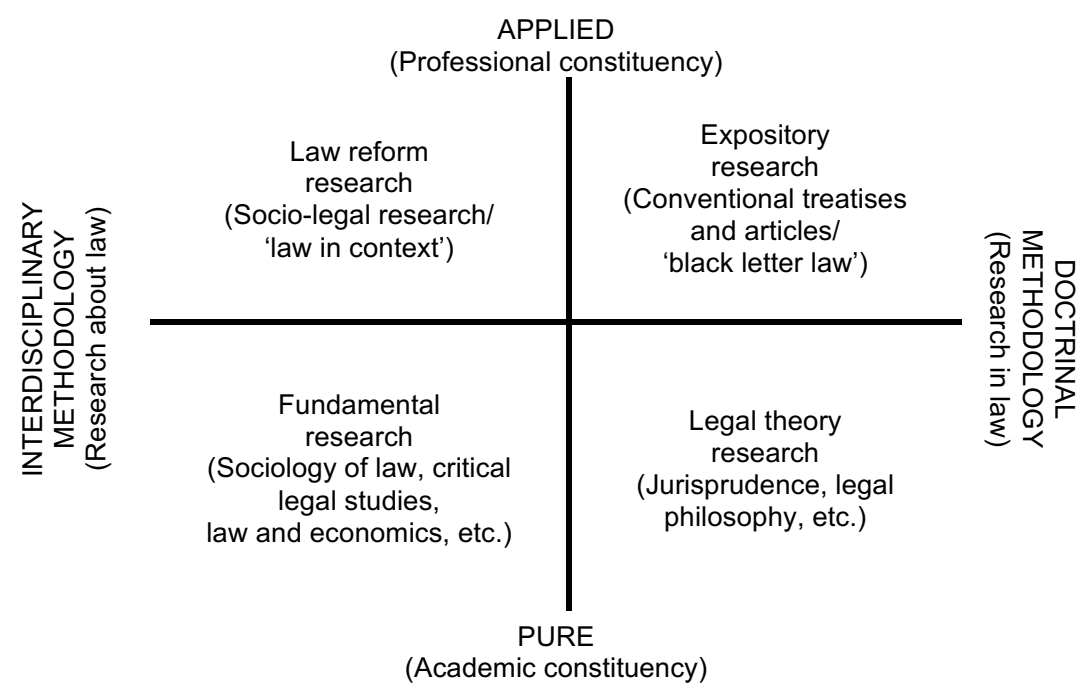

The horizontal axis in Figure 1 represents legal research as a spectrum of methodology from legal doctrine to interdisciplinarity, while the vertical axis spans research that is professionally orientated, to the more academic. The resulting four quadrants describe black letter law and legal theory at the doctrinal end, and law reform and fundamental research at the interdisciplinary end.

These four broad areas of legal research potentially encompass diverse methodologies, and scholars particularly at the interdisciplinary end of the spectrum would likely require explicit knowledge of research methods and methodologies beyond pure law. At the same time, the hallmark of doctrinal legal research is what might be described as a lack of self-awareness as to method, and the question of methodology is not an easy one to answer for many legal scholars.

...it is probably incorrect to describe the process of legal analysis as being dictated by a 'methodology', at least in the sense in which that term is used in the sciences. The process involves an exercise in reasoning and a variety of techniques are used, often at a subconscious level, with the aim of constructing an argument which is convincing according to accepted, and instinctive, conventions of discourse within the discipline. ${ }^{26}$

As a consequence, and as Roux observes, doctrinal legal scholars may find it difficult to articulate their research method and methodology in the way that is accepted in other disciplines. ${ }^{27}$ This may even be the case for some legal scholars who implicitly

\footnotetext{
${ }^{26}$ Paul Chynoweth (2008) 'Legal Research' in Andrew Knight and Les Ruddock (eds) Advanced Research Methods in the Built Environment, 28, 34-5.

${ }^{27}$ Theunis Roux 'Judging the Quality of Legal Research: A Qualified Response to the Demand for Greater Methodological Rigour' (2014) 24(1) Legal Education Review 177 ('Qualified Response'). Cf some detailed exploration of research methods in, eg, Terry Hutchinson, Researching and Writing in Law (2 $2^{\text {nd }}$ ed, Thomson, 2006).
} 
incorporate diverse methods, approaches, or methodologies as part of their 'argumentative machinery' ${ }^{28}$ within what they may perceive to be doctrinal research.

The development of legal research beyond doctrine has been described elsewhere. Collier, for example, claims that 'we are all socio-legal now' ${ }^{29}$ Burns and Hutchinson point out that 'as researchers, lawyers need to be totally cognisant of the parameters of empirically-based knowledge and research methodologies. ${ }^{30}$ In particular, they argue for enhanced training in 'fundamental research' as an integral part of law discipline research methods. ${ }^{31}$

By contrast, Thornton has articulated the loss of critical legal scholarship in the academy in Australia. She argues that legal scholarship and law schools in general, are techno-centric and corporatist tools of neoliberalism. ${ }^{32}$ However even this view might recognise the evolution of legal research beyond doctrinal boundaries.

Competition for funding, for example, implicitly drives the nature of research to instrumentalist ends defined by institutional, corporate, or governmental objectives that may bear no relationship to discipline values or imperatives. Debates about 'impact' and measurement of 'quality' and productivity, likewise are likely to affect the goals and methods of legal research. Where these measures are not concordant with doctrinal traditions, they will necessarily generate new avenues of inquiry and altered conceptions of legal research. ${ }^{33}$ Of note, following the now officially abandoned journal rankings exercise in Australia, no specialist journals in legal education achieved an $\mathrm{A}^{*}$ ranking, and a significant majority were ranked $\mathrm{C} .{ }^{34}$

Regardless of the broader landscape of research within higher education, it is likely that legal scholars and colleagues in the profession will continue to focus on discipline-oriented research practice. Roux, for example, captures the inherent coherence of doctrinal research.

The crucial defining feature of doctrinal research is that it is offered as a participant act in a particular legal system. Unlike other academic disciplines, doctrinal

\footnotetext{
${ }^{28}$ Theunis Robert Roux, 'The Incorporation Problem in Interdisciplinary Legal Research: Some Conceptual Issues and a Practical Illustration' (2015) 2 Erasmus Law Review 39 ('Incorporation Problem'), 59.

${ }^{29}$ Richard Collier, "“We're All Socio-Legal Now?” Legal Education, Scholarship and the "Global Knowledge Economy” Reflections on the UK Experience’ (2004) 26(4) Sydney Law Review 503.

${ }^{30}$ Kylie Burns and Terry Hutchinson 'The Impact of "Empirical Facts" on Legal Scholarship and Legal Research Training (2009) 42 (3) The Law Teacher 153, 159.

31 Ibid.

${ }^{32}$ See, eg: Margaret Thornton 'Inhabiting the Neoliberal University' (2014) 38 Alternative Law Journal 2; Margaret Thornton, 'The Demise of Diversity in Legal Education: Globalisation and the New Knowledge Economy' (2001) 8(1) International Journal of the Legal Profession 37; Margaret Thornton and Lucinda Shannon, "Selling the Dream': Law School Branding and the Illusion of Choice' (2013) 23(1/2) Legal Education Review 249; Margaret Thornton, 'Discord in the Legal Academy: The Case of the Legal Scholar' (1994) 3 Australian Feminist Law Journal 53.

${ }^{33}$ See, eg, Sheila Slaughter and Larry L Leslie, Academic Capitalism: Politics, Policies, and the Entrepreneurial University (John Hopkins University Press, 1997); Mary Henkel, 'Academic Values and the University as Corporate Enterprise' (1997) 51(2) Higher Education Quarterly 134; Kathy Bowrey, 'Audit Culture: Why Law Journals are Ranked and What Impact This has on the Discipline of Law Today’ (2013) 23(2) Legal Education Review 291.

${ }^{34}$ See, eg, Kathy Bowery, 'Assessing Research Performance in the Discipline of Law: The Australian Experience with Research Metrics, 2006-2011' (Report to the Council of Australian Law Deans, 2012) $<$ http://cald.asn.au/assets/lists/Resources/Prof\%20Kathy\%20Bowrey\%20Research\%20Quality\%20Rep ort $\% 20$ to $\% 20$ CALD.pdf $>, 86$.
} 
researchers are not primarily addressing a scholarly community, but a legalprofessional community engaged in a joint enterprise of constructing legal doctrine. ${ }^{35}$

Roux also acknowledges the complexity of situating doctrinal research purely within the discipline of law. He observes, for example, that some claim that legal method is inherently interdisciplinary. ${ }^{36} \mathrm{He}$ concludes however, that while legal method - in the context of doctrinal research-draws on diverse analytic traditions,

for the pure doctrinal researcher, reference to other disciplines always occurs on law's terms, with a view to improving the quality of legal doctrine. There is never any thought of subordinating the conventionally accepted reasoning techniques in the legal tradition in which they are working to the methods of another discipline. ${ }^{37}$

Thus, beyond doctrinal research, legal research retains a discipline-orientation regardless of the introduction of interdisciplinary methods and methodologies. Whether self-consciously interdisciplinary or not, research in the discipline of law that is a 'participant act in a particular legal system', ${ }^{38}$ whether engaging in interdisciplinary methods or not, remains legal research. ${ }^{39}$

\section{SCHOLARSHIP OF LEGAL EDUCATION}

The way in which we understand legal research has implications for scholars of legal education. Legal research was long seen as fundamentally about explication of legal doctrine and legal theory, and very strongly practitioner oriented. ${ }^{40}$ Socio-legal research where the approaches of social science research are as important as doctrinal perspectives was often on the fringes of Australian and English research, though it has a stronger history in the US through movements such as the Legal Realism, and Law and Economics. ${ }^{41}$ More recently, socio-legal research has come to have much greater prominence, possibly through the synergy between it and grant funding - now a strategic driver of university research focus. ${ }^{42}$ Legal education research, not having similar access to prestigious funding, has remained on the fringes.

Despite some SoLE concerning itself with the teaching of doctrine, its method and concerns cannot be said to be doctrinal per se. For example, such scholarship does not engage with deficiencies in the law itself. ${ }^{43}$ Indeed, increasingly, SoLE adopts empirical and even scientific methods ${ }^{44}$ that are obviously other than doctrinal, and outside the traditional research toolkit of the legal scholar. Consequently, and to the extent that engagement in doctrine represents legal scholarship, legal education

\footnotetext{
${ }^{35}$ Roux, 'Incorporation Problem', above n 28.

${ }^{36}$ See, eg, Timothy J Berard, 'The Relevance of the Social Sciences for Legal Education' (2009) 19(1)

Legal Education Review 189.

${ }^{37}$ Roux, 'Incorporation Problem', above n 28 (footnotes omitted).

${ }^{38}$ Ibid.

${ }^{39}$ Similar conclusions can be drawn from the analyis in Siems and mac Síthigh, above n 19.

${ }^{40}$ Ibid.

${ }^{41}$ Sugarman, above $\mathrm{n} 5$.

${ }^{42}$ See the review of this in Susan Bartie, 'The Lingering Core of Legal Scholarship' (2010) 30(3) Legal Studies 345.

${ }^{43}$ Roux, 'Qualified Response', above n 27, 178.

${ }^{44}$ See, eg Wendy Larcombe et al, 'Does an Improved Experience of Law School Protect Students Against Depression, Anxiety and Stress? An Empirical Study of Wellbeing and the Law School Experience of LLB and JD Students' (2013) 35(2) Sydney Law Review 407.
} 
research has to date enjoyed somewhat of an 'outsider' status within the Australian legal academy.

On the other hand, SoLE does resonate with Roux's observation of the purpose of doctrinal legal research, which seeks to

...persuade other legal professionals - fellow legal academics, practising lawyers, judges and law reformers - of the researcher's understanding of the state of the law and the seriousness of any deficiencies identified. Understood in this way, doctrinal research is research conducted by legal insiders for other legal insiders. It has no purpose beyond convincing other actors in the legal system of the merits of the argument made out. ${ }^{45}$

Rather than focusing on legal doctrine per se, legal education research seeks to improve the quality of legal education, within the law's terms of what is appropriate to serve discipline requirements of students in law, and of law graduates. The audience is inward-looking, likely to be the legal-professional community rather than educators more broadly. On this basis, scholarship in legal education performs the role of developing the practitioners who themselves will construct the law. Legal education might thus itself be seen as constructing the law.

The challenge for categorising SoLE might be better understood through appreciating its character both as legal and as educational. For example, to the extent that legal education research engages in interdisciplinary methods, Roux identifies a 'problem of belonging':

...research ... that attempts to integrate the internal doctrinal perspective of the trained lawyer with the external perspective of one or more other disciplines ... [generates] a practical problem of belonging - of being forced to choose between two audiences: the legal-professional community and the wider academic community. It is also partly a philosophical problem in as much as it raises the question, common to all interdisciplinary research, of whether it is possible to participate in two different practices at the same time. ${ }^{46}$

Thus, for some the scholarship of legal education may be educational research: it is not 'proper law' at all. Adopting Roux's explanation, scholars in legal education face a philosophical problem of whether it is possible to be simultaneously a scholar of education and a legal scholar. ${ }^{47}$ They face the additional problem of whether to write for a general education audience, or a legal education audience.

The characterisation of legal education research may appear a somewhat abstract problem, however it has important implications for the development of legal education, and thus, we argue, for the development of the practice of law. To the extent that discipline frameworks reject scholarship in legal education as 'outsider' research, law schools will not value it and legal academics will not research in legal education. A discipline-wide lack of engagement in the scholarship of legal education

\footnotetext{
45 Roux, above n 43, 178.

${ }^{46}$ Roux, 'Incorporation Problem' above n 28.

${ }^{47}$ Similar issues are raised in Marilla Svinicki, 'Who Is Entitled to Do SoTL?' (2012) 6(2) International Journal for the Scholarship of Teaching and Learning $<\mathrm{https}$ ://digitalcommons.georgiasouthern.edu/ij-sotl/vol6/iss2/2>.
} 
will only reinforce perceptions of its outsider status according to institutional metrics of 'quality', a point made by Bowery in the context of journal rankings. ${ }^{48}$

To retain a vibrant and rigorous culture of scholarship in legal education, requires institutional support. Further, law schools - and the profession - have a vested interest in high quality scholarship of legal education not only as consumers of the resulting research 'outputs', but also as stakeholders in the efficacy of legal education to serve society and the profession, while employing and advancing contemporary educational imperatives and methods. The scholarship of legal education functions at the intersection of higher education, the law school, the legal profession, the law, the community, and law students.

SoLE is thus legal scholarship. Its adoption of education or social science research methods occurs on law's terms. Such research is aimed at a legal audience, and it concerns the education of lawyers.

The knowledge system to which legal researchers are contributing ... is not the privately produced, corrigible work product of a purely academic discipline, but the state-sanctioned legal system, with its corpus of authoritative norms and its conventionally accepted ways of working with those norms. ${ }^{49}$

SoLE engages with those 'authoritative norms' through the lens of how best to educate those who apply them. It presents, re-presents, and adapts the modes by which new lawyers are inculcated into working with those norms. To construe SoLE as interdisciplinary implies a bifurcation of audiences where one audience is engaged in the construction of legal practitioners, and the other is concerned with education, or work, or some other discourse. We suggest that for the most part, it is more accurate to describe SoLE as legal research, incorporating diverse methods, and concerned with the education of lawyers.

\section{A TAXONOMY OF SOLE}

Sitting as it does at the juncture of academia and practice, law and education, a taxonomy of SoLE would be expected to encompass diverse influences both in terms of content, and in terms of method.

The aim of this undertaking is to attempt to capture these influences in a taxonomy that represents a reproducible method of describing and therefore understanding knowledge production within the sub-discipline area of legal education, and for managing that knowledge. Examination of legal education literature in terms of a taxonomy facilitates reporting, planning and coordination, ${ }^{50}$ to reveal trends and opportunities for new research.

The taxonomy developed here is based on three dimensions: perspectives, research method, and legal education theme - together describing the 'who', 'how', and 'what'

\footnotetext{
${ }^{48}$ Bowrey, above n 34.

${ }^{49}$ Roux, above n 28.

${ }^{50}$ See, eg, Uber Research, 'Research Classification Approaches: Stamping or Understanding?' (11 March 2014) < https://www.uberresearch.com/uberresearchWP092014/wp-content/uploads/CASRAIReConnect-Research-Classification-1-UberResearch March-2014.pdf $>$.
} 
of research. Each dimension itself comprises a classification system. We describe each in turn.

\section{A. Perspectives}

The first dimension of our taxonomy we call perspective, addressing the 'who' and 'whom' - the authorial voice and object of the work (see Figure 2). Perspective addresses the subjective purpose or philosophical framework that the author adopts in their inquiry. We envisage these author perspectives as a hierarchy, reflecting a Bloom's-style evolution from lower to higher orders of abstraction. The hierarchy thus frames an author's approach to the subject matter from its description, through historical, theoretical, empirical, and critical lenses, to radical critique.

We have derived these categories as subject-matter experts, followed by refinement through testing upon a small sample of SoLE literature. ${ }^{51}$ Some were in part informed by approaches to educational research, ${ }^{52}$ but reflect also the diversity in legal method. This part of the classification may thus provide the potential for connection with legal research. Similarly, and as reflected in Tight's taxonomy of higher education, ${ }^{53}$ we have identified likely objects of the research.

Figure 2

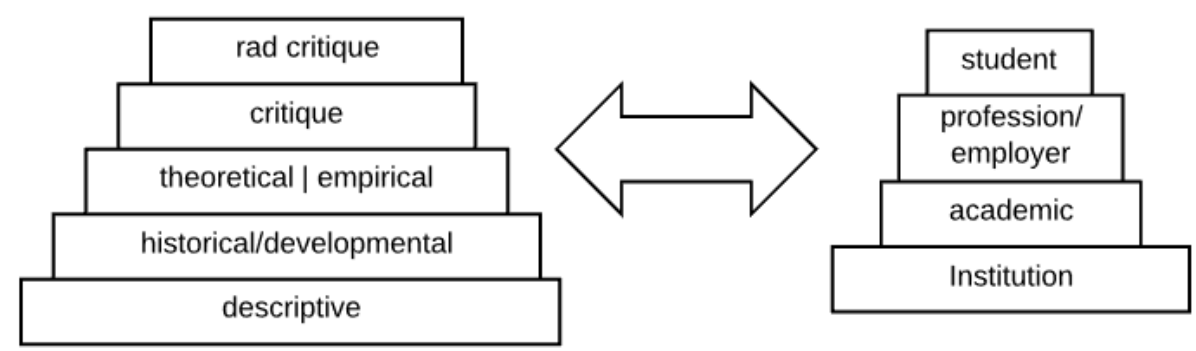

The hierarchical nature of this classification is based on an analytical logic, not a judgment on quality or importance. Valuable and exacting scholarly work occurs at all levels in the hierarchy, our hierarchy is intended to capture the extent to which a scholar moves outside of law's methods. We see this as important in highlighting the way SoLE interacts with other disciplines and research traditions.

Description captures the important work of describing a field of legal education, whether environmental, historical, developmental or otherwise, and places findings in accepted approaches or categories of teaching or pedagogy. ${ }^{54}$ In legal education such

\footnotetext{
${ }^{51}$ A small sample of legal education research was reviewed - namely articles published in the Legal Education Review 2016-2017-to test our categories and assumptions. A deeper survey is anticipated. See Part V below.

${ }^{52}$ For example, see Lawrence Manion, Louis Cohen and Keith Morrison, Research Methods in Education (Routledge, 2007), chapters 1, 8, who outline critical approaches as well as historical and documentary approaches, amongst others.

53 Tight, above n 19, Part II.

${ }^{54}$ In terms of legal research outside of SoLE this could be seen as doctrinal analysis within the accepted forms of the profession. Thus an analysis that highlights overlooked precedent cases, that
} 
analysis would include the matching of identified approaches to law teaching or pedagogy with existing categorisations in either law teaching or teaching more generally.

Often however, research goes beyond these bounds and attempts to reorganize knowledge on a theoretical basis, or to gain new understandings on an issue by analysis of empirical findings. However, the extent to which that theory or empirical research creates new perspectives varies. Thus, the hierarchy recognises that the use of theory or empirical evidence may be an extension of a historical/developmental approach, or it may be the basis for a greater critique of the area of knowledge. The hierarchy also recognises that such critique can run within existing channels of thought, or be a radical rethinking. It is important to note however that the hierarchy is one of abstraction from existing knowledge and practice, not in any way a suggestion of increased scholarly merit.

Beyond the theoretical or ideological positioning of the author, we recognise that empirical or theoretical hypotheses are applied to particular subjects, whether human or institutional, concrete or abstract. We therefore suggest that the 'who' of scholarship embrace not only the authorial voice, but the objects of SoLE. As noted in Figure 2, the categories that emerged from the pilot study are, hierarchically, the institution, the academic, the profession or employer, and the law student.

SoLE works engage with the role of the university or faculty in legal education, as well as the perspective of the academic. There is a literature concerning the relationship between the profession or employment on legal education, as well as research into the law student experience and the law student as a learner. We suggest that these may be aligned, or in tension, with authorial voice. The literature serves to reflect our interests as academics, for example, while also providing a forum for challenging institutional norms either of the university, or even of the profession. In this way we see the 'who' as connecting both the author's standpoint, as well as the object of the study.

This hierarchy again is not based on increasing merit. Instead the classification seeks to highlight the degree of indirectness to the object of legal education. That is, education is ultimately about the student and their experiences, but research into that can be mediated through analysis of the needs of the profession, the approaches of individual teachers, and broader institutional impacts on teaching and learning.

While this dimension provides information about the perspective of the research, to garner a deeper insight into the multidisciplinarity of the research requires investigation of the 'how'-ie the research method.

\section{B. Research Method}

In recognition of the influence of the discipline of education upon the SoLE, we have adopted classes of educational qualitative methods to describe our second dimension: the method of inquiry. 
Despite the tradition of schooling lawyers, including legal academics, in doctrinal method, increasingly legal scholars are educated in diverse methods. This can be seen through the growing number of empirical studies in legal education research. ${ }^{55} \mathrm{In}$ some cases, however, it is likely that legal scholars may engage in interdisciplinary methods without a foundation knowledge of that method. Roux warns against this as an easy alternative, instead suggesting that legal scholars 'should pay rigorous attention to the conceptual frameworks and methods of all the disciplines on which they are drawing. ${ }^{56}$

Yet on the other hand the rationale for the emerging field of the 'scholarship of teaching and learning'(SoTL) is that interdisciplinary scholars are not equally expert across all their fields, and consequently may need to research in teams, or recognise their developing expertise. ${ }^{57}$ As we point out above, SoLE is also a field of research for the discipline of law and so mediates and translates between the epistemological viewpoints of various research traditions.

We chose for the starting point of our taxonomy to adopt recognised frameworks of educational research methods: naturalistic and ethnographic; historical and documentary (to which we add theoretical); surveys, longitudinal, cross-sectional and trend studies; internet-based research and computer usage; case studies; ex post facto research; experiments, quasi-experiments, single-case research and meta-analysis; and action research. ${ }^{58}$

None of these methods intersects with classical doctrinal legal research. Consequently, classification in this dimension is merely descriptive of accepted research classifications. Like education research itself, the classification is broad and catholic and open to approaches to research

\section{Legal Education Themes}

The third domain we describe as themes of legal education research. Themes relate to recognised trends in legal education research and practice - recently exemplified, for example, by the interest in student wellbeing. While some themes represent a particular period, others persist over time. These themes might be reflected in educational contexts more broadly, but the themes we focus on are emblematic of the concerns of the legal education with a view to admission to the profession.

While we initially anticipated most of the themes as subject experts - such as wellbeing, Indigenous perspectives, skills, alternative dispute resolution, internationalisation, critical thinking, work integrated learning, technology and law, gender, doctrine, and regulation - others became apparent as we tested our initial categories on the sampled articles. As we describe below, the classification of legal education themes evolved from an inventory into a true classification.

In addition to themes shared with the legal profession or specific to the law, there were some others that arose principally in the context of higher education. Notably,

\footnotetext{
55 See, eg, Alex Steel's bibliography of empirical research. \#\#\# Need full Reference\#\#\#

${ }^{56}$ Roux, above n 43, 194. See also Burns and Hutchinson, above n 30.

${ }^{57}$ See eg Svinicki, above n 44; Colleen Tremonte, 'Window Shopping: Fashioning a Scholarship of Interdisciplinary Teaching and Learning' (2011) 5(1) International Journal for the Scholarship of Teaching and Learning <https://digitalcommons.georgiasouthern.edu/ij-sotl/vol5/iss 1/26>.

${ }^{58}$ Manion, Cohen and Morrison, above n 52.
} 
these include the first-year experience and the student experience, as well as theories of learning. The former encompass questions of equity and diversity, but as with the latter, they also reflect explicit curricular and pedagogical — ie educationalimperatives. These take on a particular complexion in light of the law itself, and its practice where equity and diversity are at the forefront of concerns with progressive reform.

Through this process we labelled what we perceived to be the key themes in legal education research. The next step is classification-which we address specifically in the next part.

\section{ClassificAtion of LEGAL EduCATION Themes}

In designing the classification, we have adapted the approach of Waltman and van Eck, ${ }^{59}$ comprising three steps:

1. Labelling research areas;

2. Determining the relatedness of publication themes; and

3. Clustering publications into research areas.

These three steps are relevant to our project in that they indicate a process for sorting a classification. Tight, for example, offers a ready-made classification of themes in higher education research. ${ }^{60}$ However, his classification relates to higher education generally and is therefore too broad for our purposes - in particular in light of our interest in the connection with legal research. Further, he has derived two classifications, according to a survey of both journals and books separately. By contrast, we seek to derive a classification that can be applied across the literature.

While Waltman and van Eck first determine relatedness of publications followed by clustering and labelling, we have adjusted the sequence of classification stages. In common with Waltman and van Eck, our taxonomy may serve a bibliometric purpose which they identify as including 'simplify[ing] literature search, study[ing] the structure and dynamics of scientific disciplines, or to facilitate bibliometric research evaluations. ${ }^{61}$ However there are fundamental differences in both scope and purpose of our study.

First, unlike the sciences - the subject of Waltman and van Eck's study - law is a self-contained discipline. We have noted, however, the challenges of comprehending legal education research within the law discipline proper, and the rationale for offering a bridge between the two. While bibliometric goals will facilitate this, these are secondary to the purpose of locating the discipline context of legal education research.

Secondly Waltman and van Eck dealt with a huge data set of almost 10 million science publications. The field of legal education - a discrete field at that - is far smaller. While there are inevitably ways of testing the outcome of this pilot using data

\footnotetext{
${ }^{59}$ Ludo Waltman and Nees Jan van Eck, 'A New Methodology for Constructing a Publication-level Classification System of Science’ (2012) arXiv:1203.0532 [cs.DL].

${ }^{60}$ Tight, above n 19, 20, 43, summarising themes for journals and books respectively.

${ }^{61}$ Waltman and van Eck, above n 59, 1.
} 
sets of publications globally and drawing on electronic databases using algorithmic analysis, ${ }^{62}$ our purpose at this stage is to map likely legal education themes.

Like Waltman and van Eck, we have aimed in this method to adopt a transparent and simple system. By contrast however, we have engaged human knowledge in our method, excluding digital solutions. ${ }^{63} \mathrm{We}$ envisage that our pilot program might form the basis for digital analysis at a later stage.

As described in traditional library classification, our method involves the classification of knowledge represented in the legal education literature, using logic to generate divisions. Mills suggests two principles. The first is that 'one principle of division only should be applied at a time; as a result, subclasses should be mutually exclusive.' ${ }^{64}$ The second is that 'steps of division should be proximate-that division "should not make a leap". ${ }^{65}$

Applying these principles generates divisions in which the most general, or indeed least significant category comes first, while the most significant or focused category comes last: 'the more concrete will follow the less concrete'. ${ }^{66}$ While library classification, for example, works through divisions, facets, subclasses, and foci, ${ }^{67}$ we have adapted this terminology for our purposes, describing principal divisions, and facets as the most specific end point of the classification process.

As Mills points out, 'faceted classification' ie building a system of categories that recognises the faceted categories of subject matter, derives its facets... from an examination of the literature'. ${ }^{68}$ We commenced the classification process drawing on our combined subject knowledge, anticipating the facets displayed in the literature and comparing our individually-derived results. We then tested these facets against a small sample of articles in the Legal Education Review, over 2016-2017. We will continue to refine the themes classified in an iterative process of returning to the SoLE literature and adjusting the themes based first on the discovery of new facets of the field, and secondly on the relevance of any new theme to a cluster of publications. In other words, in the third stage of the project, if there is no cluster around a theme, then there is little imperative to retain it.

Through this method we have so far identified three primary divisions, and a total of 24 facets - illustrated in the diagram below. We describe the scope of these divisions in the following discussion. The first, Curriculum, refers to the institutional structures, syllabus ordering and content, and the implicit and explicit aims of legal education. Secondly, Pedagogy refers to the processes of legal education with a focus on the practices and philosophies of teachers and broader social expectations of education. Finally, Learning refers to the actual internal processes of students studying law, and the external encouragements, pressures and impacts on that learning.

\footnotetext{
${ }^{62}$ For example, see Kristoffer Greaves, 'A Meta-survey of Scholarship of Learning and Teaching in Practice-based Legal Education. \#\# Later Editorial Stage insert cross reference\#\#\#

${ }^{63}$ Waltman and van Eck, 2.

${ }^{64}$ Mills, 27.

${ }^{65}$ Mills, 35.

${ }^{66}$ Mills, 34.

${ }^{67}$ Mills, 15.

${ }^{68}$ Mills, 10.
} 
In Ben Golder, Marina Nehme, Alex Steel and Prue Vines (eds) Imperatives for legal education research: then, now and tomorrow (Routledge, 2020) 

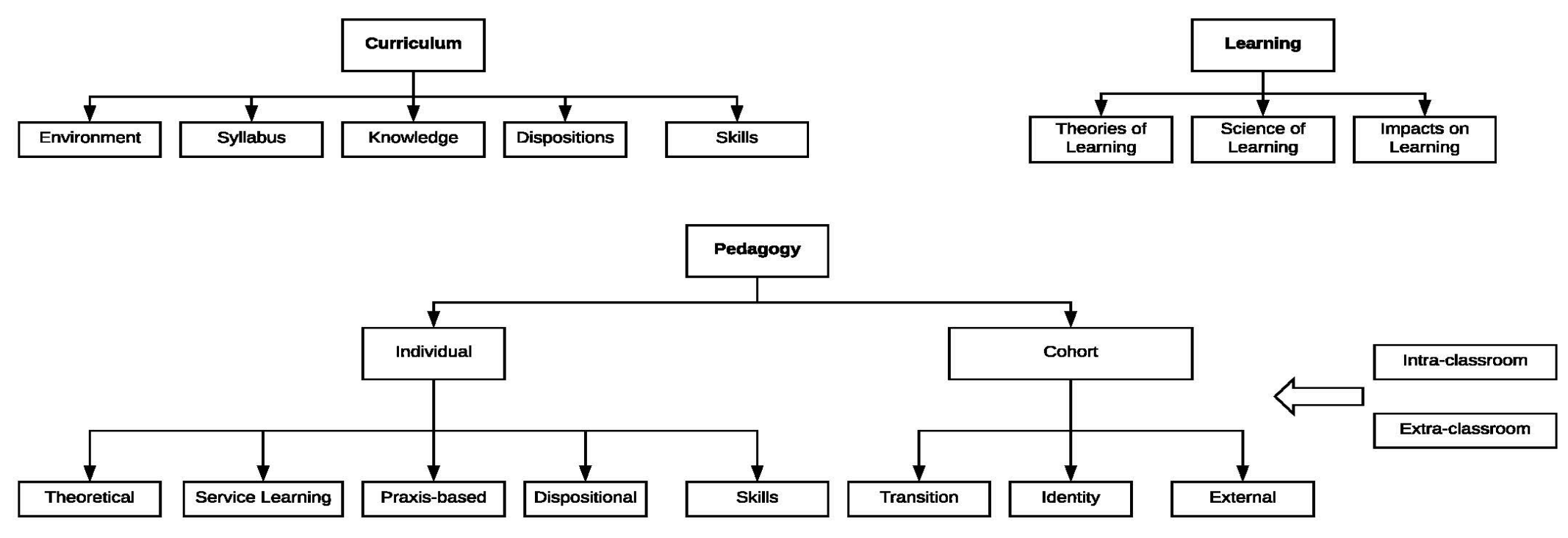


\section{A. Curriculum}

Curriculum is the first of three primary classifications. It addresses the various elements of the design of any program of law studies. 'We may take a curriculum in higher education to be a pedagogic vehicle for effecting changes in human beings through particular kinds of encounter with knowledge. ${ }^{69}$ By extension, curriculum is a prerequisite of any intentional legal education. We have drawn five secondary themes within Curriculum; Environment, Syllabus, Knowledge, Dispositions and Skills.

Environment encompasses all factors that affect legal education outside of the syllabus. This includes university and government policy and politics, legislative requirements for admission, broader social factors on higher education.

Syllabus encompasses all the aspects of designing and arranging the course of studies in law, including the learning resources made available to students such as texts and digital media, assessment (including a variety of types, such as formative, summative), and learning outcomes. With Syllabus we identify three key areas of research:

Knowledge relates to the content of legal education. While doctrinal research into 'the law' is primarily seen as traditional legal research, research that interrogates what content is most appropriate for achieving syllabus learning outcomes can be seen as legal education related. It is likely to intersect with other foci such as learning engagement.

Dispositions, including research into defining the required values and selfawareness of the law student, encompasses work that engages with the construction of identity, be it as a lawyer, a law student or a member of the profession generally. Work in this theme might take an autoethnographic approach, a sociological approach or adopt reflective methodology to interrogate the nature of professional or personal identity within the legal discipline.

Skills, embracing key skills expected and required of law students and graduates, in order that they progress through their legal education and meet graduate outcomes. Work in this theme often articulates the mastery of reading for meaning, competence in communication (including oral and written manifestations of legal concepts, professional engagement and personal interactions), along with competence in collaborative work and negotiation work, and the skill of 'thinking'. By thinking we refer to the mastery of legal reasoning and analysis, which includes legal problem solving, reflective thinking, critical thinking and creative thinking.

\section{B. Pedagogy}

\footnotetext{
${ }^{69}$ Ronald Barnett, 'Knowing and Becoming in the Higher Education Curriculum' (2009) 34(4) Studies in Higher Education 429, 429.
} 
Pedagogy is the second of the three key classifications. 'Pedagogy may be construed as the formation of a set of principles upon which teachers can assist students in moving effectively and efficiently from a relative state of ignorance to a state of wellfound knowing. ${ }^{70}$ It emphasises intentional strategies deployed to achieve learning beyond 'encounters with knowledge' per se. ${ }^{71}$ Recognising the distinction between curriculum and pedagogy, in this theme we have brought together the methods of teaching in legal education and sought to draw out the different modes of engagement with the student learner. We suggest that it encompasses classroom issues (both intraand extra-classroom), and student cohort matters. Further, we identify in the pilot project two distinct strategic approaches in pedagogy research: Individual and Cohort Pedagogy; and a third factor we call Pedagogical Modalities.

The first, Individual Pedagogy, is aimed at each student individually and largely ignores broader environmental factors. While the success of such strategies may involve empirical testing across cohorts of students, that is not its starting point. Within this focus is a range of practical and theoretical approaches.

Theoretical approaches to Pedagogy develop overarching philosophies to support practice. Examples include contextual theories of legal education argued for by such writers as Twining, broader liberation pedagogies, such as Friere's, and so on.

Service learning is a form of community engagement pedagogy, combining learning outcomes and community service to enhance both student development and the common benefit. Student learning then emerges by way of experience in a cycle of guided action and critical reflection, with the goal of community benefit and grounded learning based in experiential activities and meaningful motivations.

Praxis-based pedagogy research would include those forms of scholarly endeavour that seek to use teaching practice in reflective ways, and broader notions of SOTL.

Dispositional and Skills Pedagogies focus on the traditionally implicit aims of legal education - considering best to teach to 'think like a lawyer' and the teaching of ethics, ethical practice and professionalism.

The second main classification, Cohort Pedagogy, aims to identify broader cohorts and build pedagogic strategies for those groups. It addresses specific strategies to assist groups of law students that centre on a shared characteristic of that group - as opposed to strategies applied to individuals. As such we have identified three subthemes: Transition, Identity and External.

Transition considers the way cohorts move into and through and beyond legal education. Such transitions include the move from secondary to tertiary studies; from non-law to law studies at a graduate level; from novice to expert

\footnotetext{
${ }^{70}$ Ibid 432.

${ }^{71}$ Ibid.
} 
in relation to individual subject areas, skills or dispositions; or from tertiary studies into the profession.

Identity examines how cohorts of students see themselves or are seen by others and how that impacts their legal education. These can include identification in exclusive or inclusive ways, and involve intersecting identities. The theme includes research into the legal education of for example, international or domestic students, students who are the first in family to study at university, Aboriginal and Torres Strait Islander students and other ethnicities, male, female students, LGBTQI students and examination of cohort-based diversity and inclusion pathways.

External considers the range of factors external to student's own efforts that impact on their learning. These factors can include the time demands of study, physical and digital learning environments, the extent of learning support services, broad study stressors or events, lifestyle impacts, the market for job seekers and predicted future work environments.

In each of these subthemes, the emphasis is on pedagogical approaches to legal education that can assist these cohorts. Examination of the individual reasons for students being in transition, identifying with a particular cohort or being hindered by external factors is classified below in the Learning classification, though it is recognised that a research project is likely to involve more than one classification.

In addition to these two main Pedagogy classifications we recognise that pedagogical strategies often differ depending on the Modality of teaching. To assist with identifying these modalities we suggest the following terminologies. We use the term classroom to denote the place of delivery. In this sense we can suggest that there are two key classifications; intra- and extra-classroom.

Intra-classroom describes the learning spaces mediated by the university, whether it be the lecture room, online learning platform, real time streaming of lectures or engagement on a specialised software platform (eg Second Life). This can be further sub classified into practice-oriented modes - such as simulations and mini-moots, and academic approaches that represent a traditional focus on intellectual knowledge such as lectures, discussions and group-work.

Extra-classroom learning spaces involve work integrated learning experiences such as internships, externships and placement programs. In addition, we include clinical and moot court programs. We acknowledge that these can sometimes occur on university premises, including in faculty-run clinics and mooting programs. But equally there are many clinical and mooting experiences that take the student beyond universitymediated spaces. In both cases, these spaces are thus differentiated in their purpose from the traditional classroom experience.

\section{Learning}

This final classification captures research that examines the nature of learning in a legal context. Again, drawing both on our understanding of the field, the literature broadly, and the small sample of articles reviewed, we posit a range of approaches that are likely to fall within this classification. 
Theories of learning refers to research that seeks to develop the conceptual frameworks that describe how law students process and retain knowledge during their studies at law school. Two examples of such approaches are constructivism, ${ }^{72}$ and threshold concepts. ${ }^{73}$

Science of learning applies research in neuroscience and psychology on how adults learn to the specific learning journeys of law students. Typically, such research is based on empirical analysis of law students undertaking discrete tasks. It may also include the application of results in non-law student cohorts to make predictions as to law student learning.

Impacts on Learning researches factors that increase or decrease student learning. These effects can be both positive and negative. It is closely linked to research into the effects of curriculum and pedagogy, but also extends beyond this to include a range of factors beyond the control of universities and teachers. Such research includes work on what affects student engagement, work on student wellbeing and resilience, and into how students develop metacognition and self-management.

\section{SoLE AS LEGAL RESEARCH: SOME CONCLUSIONS}

The prototype taxonomy of SoLE described in this chapter makes explicit the methods, approaches, purposes and subjects of SoLE. Through describing and theorising legal education research, it establishes an explicit research framework with which to substantiate the contribution of SoLE to the legal academy.

The taxonomy categorises relationships between the who, how, and what of legal education research. The 'who' - namely the object of the research and the researcher standpoint - together evidence a connection between the legal research as generally understood, and legal education research. Perspectives adopted by the author might, for example, be expected to reflect perspectives on the law itself: a socio-legal scholar might be more likely to engage with an empirical or critical approach than a purely doctrinal scholar, for example. Further, the object of the research focusing on the student, the university, the academic or the profession likewise articulates the connection between the legal education and its contribution to the practice of law.

In this respect, we suggest that the taxonomy provides the language with which to explain legal education research as deriving from and serving the purposes of the law and its practice.

\footnotetext{
${ }^{72}$ Constructivism is grounded in psychological approached to explain how students acquire knowledge and learn the law. This puts the student at the centre of the learning process, situated as an active constructor of knowledge, rather than an acquirer of information. (Dewey, Piaget). ${ }^{73}$ Threshold concepts are those fundamental understandings that go to the core of the body of legal knowledge. These might be exemplified by introductory concepts such as 'mens rea' or 'consideration', students must grasp these ideas so that core disciplinary knowledge of criminal law or contracts makes sense. These threshold concepts operate as a gateway that open the student to previously hidden ways of thinking.
} 
In terms of the 'how', we suggest that the taxonomy of methods represents the increasing interdisciplinarity of legal research per se. It serves, therefore, to reinforce the connection between this development in legal scholarship and the methods of legal education research, narrowing the perceived gap between them.

Finally, the 'what' involves themes reflecting concerns within the profession per se, and with the means by which legal education inculcates the law into a new generation of lawyers. While dealing with educational themes such as 'pedagogy' and 'curriculum' the taxonomy of themes nonetheless draws on language familiar to legal scholars as the taxonomy becomes more and more precise.

Together, and when applied to legal education research, these three domains explain that research in a way that reflects concerns of legal research more widely. Integrating these dimensions represents a new picture of research that might be comprehended as a branch of legal research. The design of the taxonomy - including three domains, the descriptors within each domain, and the hierarchy within them - might also illuminate the relationship between scholars' discipline practices in law and education, as teachers and as researchers, and as lawyers and academics. 